\title{
Anatomic and Embryological Aspects of the Cardiovascular System of Albino Wistar Rats
}

\author{
Brenno Marco De Russi ${ }^{1}$ Camila Albuquerque Melo Carvalho ${ }^{1}$ \\ ${ }^{1}$ Centro Universitário Barão de Mauá, Ribeirão Preto, SP, Brazil \\ Address for correspondence Camila Albuquerque Melo de Carvalho, \\ J Morphol Sci 2019;36:317-320. \\ PhD, Centro Universitário Barão de Mauá, Rua Ramos de Azevedo, \\ 423, Ribeirão Preto, SP, 14090-180, Brazil \\ (e-mail: camila.melo@baraodemaua.br).
}
Abstract
Keywords
- anatomy
- embryology
- heart
- morphology
- rat

The Wistar albino rat is the animal most commonly used in scientific research around the world. Knowledge of the anatomy of the body of these animals is key in the research field, especially in cases when the research requires experimental surgery. Descriptive literature on the morphology of the cardiovascular system of these animals, particularly the heart, is old and difficult to access. Publications in journals are not readily available, and books approach the subject in a superficial way. The aim of this study is to research, organize, and translate the literature on the anatomy and embryology of the cardiovascular system of the albino Wistar rat to facilitate the use of this information in future research that requires the knowledge of the anatomy of these animals, for example, experimental surgery research.

\section{Introduction}

The rat, among other animals, has been used in scientific experiments since the time before Christ, and with the intensification of research, mainly in the nineteenth century, there has been a great increase in the number of animals used. ${ }^{1}$ Although rats are the most used animals in researches, followed by mice, according to the data found in the last 4 years in databases such as Medline (85\%) and Lilacs $(70.5 \%),{ }^{2}$ the availability of information on the anatomy of these animals is rare and difficult to access.

\section{Short Communication}

As articles published in periodicals are very old, they are generally not readily available, and, moreover, there are no books with a detailed anatomical description of the heart of these animals. Thus, the purpose of this brief communication is the organization and description of these data in digital media for their democratization of .

\section{Discussion}

\section{Embryology of the Cardiovascular System}

The rat does not have brachiocephalic veins. The external jugular vein of the rats is of relatively large caliber in comparison with the internal jugular and drain portions of the head and neck. After crossing the first ribs, the external jugular veins empty into the subclavian veins along with the corresponding internal jugular veins on each side. They form two previous vena cava (superior), which enter the right atrium separately. ${ }^{3}$

The development of the previous vena cava in rats was studied in 15 embryos of different ages (from 12 days and 11 hours-16 days) to identify the progress of development. The first stage has been described at 12 days and 11 hours. The cardinal veins are short, the heart is more cephalic. At this stage, most of the segments drain into the posterior cardinal veins, with the exception of the two first cephalic segments. At 12 days and 23 hours, the embryo is typical, with previous mammal cardinal vessels nourishing and draining the head (cephalic segments), and the posterior cardinal vessels nourishing and draining the caudal region. Each corresponding cardinal vein bonds, thus forming the common cardinal vein (or duct of Cuvier), which flows into the venous sinus. The structure that will form the subclavian vein, for example, drains into the posterior cardinal vein. In the later stages, there will be a gradual change because besides the veins of the cervical segment, some veins of the upper thoracic segment begin to drain the previous cardinal veins. In the embryo at 13 days and 11 hours, the heart received

March 22, 2019

accepted

June 16, 2019
DOI https://doi.org/

10.1055/s-0039-1697008. ISSN 2177-0298.
Copyright $\odot 2019$ by Thieme Revinter

Publicações Ltda, Rio de Janeiro, Brazil
License terms

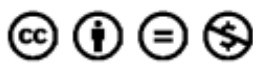


migrates caudally, and there is an increase in the number of segments linked to the previous cardinal veins. For the first time during development, the right posterior cardinal vein is lower than the left one. The cervical segments drain into the previous cardinal veins, and the thoracic segment into the posterior cardinal veins. The thoracic segments are the intercostal veins that in the adult animal drain into the azygos vein. At 14 days and 1.5 hours, the highest thoracic segment forms an anastomosis with the Cuvier duct immediately behind the entry of the posterior cardinal vein, and the subclavian veins drain the preceding cardinal vein. The posterior cardinal veins are smaller for the formation of the azygos system, and there, the posterior cardinal veins are smaller than the anterior cardinal veins for formation of the azygos system. At 14 days and 11 hours, the azygos system goes through the most relevant phase of its development. The terminology of the previous portions of the caval system can be the same as that of the adult animal. The internal jugular appears. At 16 days, the veins are almost fully developed, as they will be when the animals reach the adult stage. So, the appearance of the superior right and superior left vena cava is the result of the development of the terminal segment of the anterior cardinal veins and the Cuvier duct. $^{3}$

\section{Anatomy of the Cardiovascular System}

The mouse has a dual blood supply system in the heart. This system is found in fish and some mammals, but tends to disappear during the phylogenetic development. Halpern's studies in the 1950s concluded that the rat's heart is nourished by coronary arteries and an extracardiac system. ${ }^{4,5}$

The right and left coronary arteries are responsible for supplying the ventricles and interventricular septum. The right coronary artery is also responsible for the supply of the atrial septum. Extracardiac vessels are branches of cardiomediastinal arteries, internal mammary or the subclavian. The arteries of the right side are responsible for the supply of the right and left atria. The arteries of the left side supply a small portion of the left atrium. According to the study, this system maintains a close relationship with the right atrium and the sinoatrial node. As the mouse has this well-developed region, there is high metabolic activity that requires adequate blood supply. Moreover, the presence of this system favors searches requiring deviation in the blood stream since the supply is separated from the atria and ventricles and thus the supply of the sinoatrial node and the atrioven-

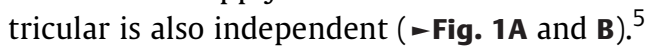

-Fig. 1: A-The figure with details of the branches of the cardiomediastinal artery in right lateroventral view. These are responsible for the nutrition of the right and left atria. Halpern ${ }^{4}$. B-The figure shows the left coronary artery and the cardiomediastinal artery with its two branches that will assist in the nutrition of a small portion of the left ventricle. Halpern ${ }^{4}$.

Another system seen in other mammals consists of veins that start in the heart and end in the previous vena cava. It consists of two major veins that cross the midline and empty into the previous vena cava contralateral to its origin. They drain the ventricular region of the right cone and the ventrocephalic region of the left ventricle. The author uses the term "extracoronary cardiac veins" because they originate in the heart, but have no relation to the coronary circulation (-Fig. 2). ${ }^{5}$

-Fig. 2: Dorsal view of the heart of an adult rat showing the relationship of the veins to the coronary sinus. Halpern ${ }^{5}$.

Studies have occasionally described some of the structures of the rat heart. Young and Fell described the vascular connections between the coronary circulation and the ventricles of the rat's heart. The veins of Tebesius are probably remaining in the adult heart, supplying made in embryonic myocardial sinusoids through vessels that connect and form the coronary veins. ${ }^{6}$

Hebel \& Stromberg describe the dynamic input and output of the arteries and veins in the rat's heart in relation to the heart chambers and some peculiarities in the macro and microscopic differences between these chambers, such as the presence of two superior vena cava. The authors refer to them as right cranial vena cava and left cranial vena cava, and
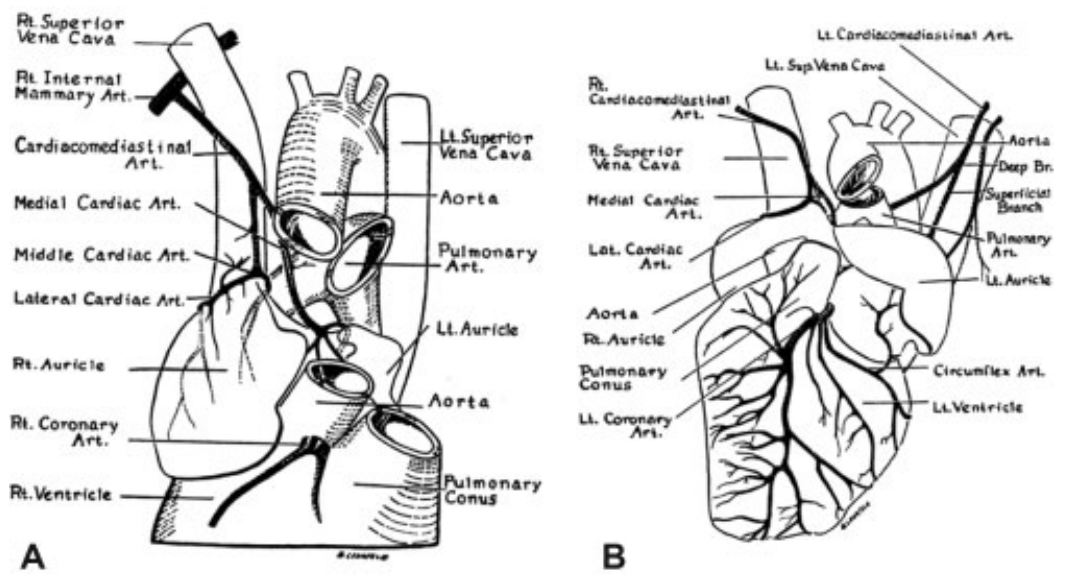

Fig. 1 (A) Figure with details of the branches of the cardiomediastinal artery in right lateroventral view responsible for the nutrition of the right and left atria. Halpern ${ }^{4}$. (B) Figure shows the left coronary artery and the cardiomediastinal artery and its two branches that will assist in the nutrition of a small portion of the left ventricle. Halpern ${ }^{4}$. 


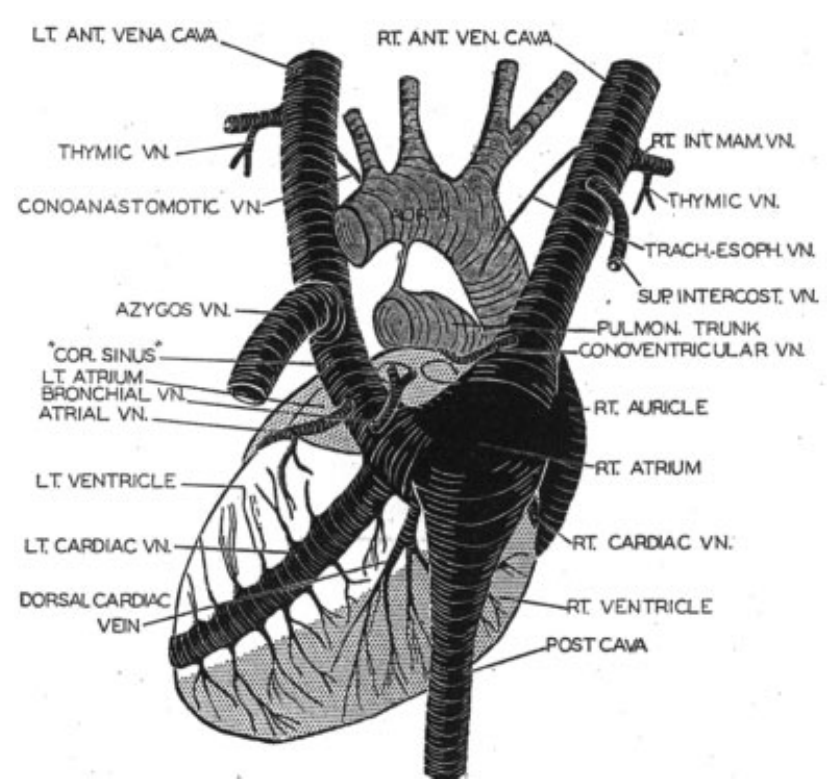

Fig. 2 Dorsal view of an adult rat heart showing the relationship of the veins to the coronary sinus. Halpern ${ }^{5}$.

they drain along with the caudal vena cava to the right atrium venous sinus. $^{7}$

Greene $^{8}$, when describing the veins of the chest, appoints the two superior vena cava in the rat: left and right. They are formed by the confluence of the internal jugular vein and subclavian on the first rib level, pass the ventral origin of the subclavian arteries and run in caudal direction until they reach the right atrium. The right vein is shorter and opens directly in the anterior portion of the atrium. The left vein extends posteriorly across the arch of the aorta, pulmonary vessels and left bronchi to enter the atrium above the inferior vena cava.

Since the persistence of two superior vena cava is a normal condition in rats, there is the formation of the right and left venous brachiocephalic trunks and their consequent fusion in the superior vena cava. The tributaries of the left vena cava are the vertebral, internal mammary, pericardial mediastinal, bronchial, superior intercostal, superior phrenic and azygos veins. ${ }^{8}$

Therefore, according to previous studies, although the rat has been used as a mammal model in several areas, such as descriptive and experimental cardiac embryology and experimental teratology, considerable variations and discrepancies have been found in the literature that have resulted in various controversies and inconsistencies. Therefore, this article aims to become an accessible and direct guide for scientific consultation. ${ }^{9}$

\section{Conflicts of Interest}

The authors have no conflicts of interest to declare.

\section{References}

1 Tirapegui J, Campos P, Ribeiro SML. O rato como animal de laboratório: histórico, dados biológicos e análise crítica de seu uso. Rev. Farm. Bioquím. Univ. S. Paulo 1995;31(01):21-28

2 Fagundes DJ, Taha MO. Animal disease model: choice's criteria and current animals specimens. Acta Cir Bras 2004;19(01): 59-65

3 Schneider LA. The development of the superior caval in the rat. Anat Rec 1938;71:265-276

4 Halpern MH. The dual blood supply of the rat heart. Am J Anat 1957; 101(01):1-16

5 Halpern MH. Extracoronary cardiac veins in the rat. Am J Anat 1953;92(02):307-327

6 Young DAB, Fell BF. Vascular connections between the coronary circulation and the ventricles of the rat heart. Anat Rec 1962; 144:149-153

7 Hebel R, Stromberg MW. Anatomy and Embryology of the Laboratory Rat. Alemanha: BioMed Verlag; 1986

8 Greene EC. Anatomy of the rat. Philadelphia: American Philosophical Society; 1935

9 Marcela SG, Cristina RM, Angel PG, et al. Chronological and morphological study of heart development in the rat. Anat Rec (Hoboken) 2012;295(08):1267-1290 